\title{
Active Citizenship or Activist Citizenship? A Framework for Studying Citizenship in New Social Movements and the Role of ICTs
}

\author{
VENETIA PAPA, Cyprus University of Technology/Université Paris 8 Vincennes- \\ Saint Denis \\ DIMITRA L. MILIONI, Cyprus University of Technology
}

\begin{abstract}
The latter half of the twentieth century witnessed an upsurge in mobilization and collective action by a wide range of activists and groups engaging in social and political protest, all over the world, which continues to this day. New media are not only greatly facilitating the ways in which activists communicate and protest, but are also altering the relation of the movements to territorial boundaries and localities. Scholars from a wide range of disciplines have tended to focus on questions about the internet's role in protest, without attempting to answer the changing meaning of what it means to be a citizen within such movements and through their practices. This article responds to this need by developing an analytical framework for studying the connection between citizenship and ICT-mediated social movements, drawing on existing scholarship on social movements, citizenship and ICTs. Specifically, using citizenship studies as a starting point, it brings together elements that are necessary for a two-level analysis: a) the tangible aspects that are seen as the concrete practices of movements and their participants and b) the ideational aspects that are seen as the abstract practices of movements and their participants. This provides a theoretical structure that facilitates connections between different disciplines that might otherwise be difficult to discern, so that the construction of citizenship can be studied on an interdisciplinary basis.
\end{abstract}

\section{KEYWORDS}

Civic engagement, civic participation, civic values, protest, ICTs.

\section{Introduction}

The impressive development, diffusion and sophistication of Information and Communication Technologies (ICTs) is a fact few would challenge; but so is the distance of citizens from formal political processes in late modern societies. At the same time, emerging social and political phenomena, such as the recent protest movements that are based extensively on ICTs for mobilization and coordination (for example, the 'Occupy' or the 'Indignados' movement), require new kinds of theorization. Current research, therefore, needs to take into account that while traditional politics seem to stagger, new sites emerge where individuals act to become citizens.

The purpose of this paper is to contribute to the vast theoretical scholarship about citizenship, aiming to better understand its changing nature within late modern ICT societies. We argue that one important question that needs to be asked is how the meaning of citizenship is being 
(re)defined today within the contours of 'new' social movements ${ }^{1}$ that draw heavily on online resources for their activities. A basic assumption is that, besides and beyond the specific political and social demands that each social movement articulates, social movements always evoke certain understandings of what it means to be a citizen. In this paper, we take up the theoretical debate of conceptualizing citizenship, in order to suggest a framework for studying citizenship within contemporary social movements.

The paper is structured as follows: in the first part, we review the basic changes citizenship undergoes in contemporary societies, where ICTs have come to play an important role as civic resources. Next, we lay out some basic facts about the social movements in question, their characteristics and their practices, focusing on the prominent role of ICTs within these processes. Then, the relationship between citizenship and social movements is explored. Lastly, we describe a preliminary theoretical framework, which could guide the empirical study of citizenship in contemporary social movements.

\section{Citizenship in Flux and the Role of ICTs: An Ongoing Process}

The decline in citizen participation in formal political activities and the disinterest of citizens towards official politics can be explained by a number of changes in cultural patterns, a characteristic related with late modernity (Putnam 2000). In a similar vein, Peter Dahlgren (2009) points out the relevance of two phenomena: individuation and the dispersion of shared unifying cultural frameworks. Individuation refers to a decrease in the feeling of social belonging, which mainly ascribes a feeling of personal autonomy. This goes hand in hand with pluralisation and 'nichification' of society in terms of media patterns, cultural interests, and lifestyles that are promoted by mass media and are fostering social orientations (Dahlgren 2009; Svensson 2011a).

Nevertheless, concerns about voter alienation, civic disinterest, distrust and delegitimization of political institutions are moderated by the rise of digital media and the internet, and more precisely its newest increasingly interactive and participatory version (web 2.0) that has sparked, once more, new hopes for democracy (Dahlgren 2002; Svensson 2011a). Central to this optimistic outlook are two elements: the online participatory patterns allowing greater civic interaction among citizens, and the online civic resources providing meaningful civic participation and engagement (Dahlgren 2009). One prominent idea here is the premise that the 'web 2.0' and other social media platforms (for example Twitter, Facebook and blogging) can offer a wide array of forms and opportunities for citizen participation. This assumption puts forward "the idea of engaged and interactive citizens" (Hermes 2006, 304). Similar gains for interaction and engagement can originate from web communities, which can serve different types of citizenship goals. As Joke Hermes argues, such practices "involve a great variety of knowledge and activities; they include emotion, sensation and experience and

\footnotetext{
1 Although the term 'new' social movements refers mainly to the social movements that emerged in the late 1960s and early 1970s (peace, feminist, environmental and student movements) with a strong concern for identity politics, in this article, this term is used in order to refer to the emergence of protest social movements since the 1990s (for example, Zapatistas, alternative globalization movement), one of their common characteristics being the intensive use of new information and communication technologies; the most recent of these movements are the Indignados and Occupy movement (see further Feixa et al., 2009).
} 
deliver, in varying degrees, a state of being informed and of commitment to larger communities" (Hermes 2006, 304).

Media theorists discuss the importance of these new configurations and the impact of new media as a set of cultural factors in citizenship. According to one of their basic assertions, the internet is seen as an opportunity structure, opening up new possibilities and opportunities for citizens in the domain of informal politics and, therefore, can help overcome all kinds of problems democracy is facing (Bennett 2003; Dahlgren 2002). As shown by a study of three websites, ICTs "are open enough to allow the production of various kinds of civic resources and the internet does not impose a uniform civic model upon the producers" (Olsson 2008, 510). The internet, thus, can produce alternative civic resources (economic, technical and discursive) readily available for citizens, and generate channels for civic engagement and participation, which in turn can engender new forms of civic identities (ibid.). Similarly, Dahlgren's framework of civic cultures adds a more obvious emphasis on the citizen, citizenship and its subjective dimensions, focusing on the mechanisms through which citizens can see themselves as members of and participants in society (Dahlgren 2009).

Dahlgren posits that civic cultures can be seen conceptually as comprised of five dimensions:

a) knowledge, ("the competencies and the skills to deal communicatively in the socio-political world"), b) values, ("substantive values such as equality, liberty, justice, solidarity and procedural ones like openness, responsibility, reciprocity and tolerance”), c) trust and affinity ("commonalities"), d) practices ("individual, group and collective practices"), and e) identities (efficacy) (ibid., 108). According to Dahlgren, "identities [are] built on knowledge and values, and can be embodied in particular spaces via practices pursuing issues by the use of civic skills that all serve to reinforce identities" (ibid., 5). Dahlgren further suggests that the newer media can be seen as a dynamic circuit that "make[s] possible new kinds of civic practices" (ibid.), and therefore reshapes the construction of civic identities.

Although these approaches and typologies are certainly analytically significant, there are three elements that render them less useful for the study of citizenship in social movements. Firstly, the focus on individual agency is an advantageous starting point for studying citizenship at the individual level, but when the focus is on collective practices and collectivities, as is the case with social movements, the collective dimension also needs to be taken into consideration. Secondly, this approach draws attention on the online practices of individuals as civic resources, disregarding the offline practices related to the meaning of citizenship, which are still significant for social movements (for example, occupation of physical spaces). Thirdly, we need to be cautious when discussing the role of technology with regard to social phenomena, so that we avoid the trap of technocentrism and technological determinism. In the next section, we will give a brief account of the social movements in question and the role of ICTs in contemporary processes of collective action.

\section{New Social Movements and their Yet Undefined Relation to ICTs}

Along with the reconfiguration and renewal of citizenship practices in late modern societies, we have witnessed the rise of a new cycle of collective action, which seems to pose new challenges to the traditional boundaries of collective action. The new wave of contention seemingly cuts across traditional cleavages by having different repertoires of resistance and 
by being marked by new digitalized contexts of participation (Feixa et al. 2009). Sociologists classify social movements using the 'old' versus 'new' social movement model, while this classification scheme is subject to important modifications in late modern societies (Bennett and Segerberg 2012; Feixa et al. 2009). The distinction between 'old' and 'new' social movements is often used in the literature to describe a particular period of history, where the movement is taking place, and the characteristics attached to it (ibid.).

The 'old' model of social movements has constituted the theoretical model per se during the period spanning more or less the $20^{\text {th }}$ century (for example, the Soviet Revolution in 1917). These types of social movements were primarily based on the ideological, social and political attributes of participants (for example, class); they were also characterized by a strong and solid social base, and by individuals sharing the same ideological beliefs, nation and social condition (Feixa et al. 2009). While their demands were attached to the 'local', they occasionally involved processes at an international level. Social movement participants had directly political demands, such as the right to vote and the equality of rights. Their focus was on traditional action repertoires, such as the strike and the demonstration. While this was the dominant model of social movements until the 1960s, new movements with different qualities arose in Europe (for example, the students' movement in Paris in 1968); this development led to a different conceptualization and categorization of collective action, based on the aforementioned new attributes.

One significant aspect of the relevant discussion has focused on the extent to which new social movements are qualitatively different from more traditional movements (Kriesi et al. 1995). New social movements are said to differ from more traditional on several accounts, such as the extension of their action towards the regional and transnational level, and the fact that their demands are often linked with cultural issues related to symbolic resources. Yet, perhaps the most distinctive characteristic of new social movements lies in their social basis. Hanspeter Kriesi and his co-authors argue that "the basic characteristic of a new social movement is constituted by the position of its main constituency in the social structure" (Kriesi et al. 1995). The 'old' social movements were based on local groups with strong internal cohesion, whereas the 'new' social movements moved away from class struggles, emphasizing identity concerns. These new characteristics of social movements have garnered a significant amount of attention in the field of sociology (Touraine 1978).

Lately, we have witnessed the rise of a wave of contention in Europe and the Arab countries (the so-called 'Arab Spring'), which presents a number of characteristics that defy the main attributes of the collective action paradigm (Anduiza et al. 2012). Eva Anduiza et al. argue that new forms of protest, such as the 'Indignados', mobilized mainly through digital media and particularly social networks, "managed to channel collective outrage through many small organizations with little resources or mobilization experience in this type of massive protests" $(2012,1)$. On a similar vein, Lance Bennett and Alexandra Segerberg introduce two new forms of digitally networked connective action "that differ from some common assumptions about collective action in social movements and, in particular, that rely on mediated networks for substantial aspects of their organization" $(2012,765)$. Their analysis is based on two elements: firstly, the political content takes the form of general frames that can be easily spread and personalized, enabling "personal engagement through easy-to share images and personal action frames" (ibid., 758); secondly, social networks allow citizens to share and diffuse resources through social networks, without depending on any formal organization or 
institutional actors, but rather using technology as their primary agents (ibid.). Similarly, Paolo Gerbaud demonstrates the importance of networks for Indignados through his concept of "choreography of the assembly", defining the networks as the symbolic construction of public space, a feeling of togetherness. He puts forward the idea that the 15-M movement in Spain used social media, and especially Facebook and Twitter, in order to construct emotional conversations and transform them into political passion, which was later transformed into collective action $(2012,100)$. Related to his notion of "choreography of assembly", the Indignados movement through "Facebook pages and Twitter feeds constructed loose collective identities characterized by an appeal to normality aiming to intercept prospective users regardless of their political and cultural affiliations" (ibid., 100).

Although the boundaries of collective action are certainly less static, there is no consensus regarding the role and the impact of ICTs on social movements. Recently, the relevant academic debate is structured between two lines of argumentation, namely the 'cyberoptimistic' and the 'cyber-pessimistic' camp. The first line of argumentation is represented by theorists, who have declared that technology, and particularly the internet, has a transformative power and can produce a variety of beneficial social and political outcomes in terms of activism (for example, Bennett 2003). More precisely, in debating the role of ICTs, many scholars advocate that the use of ICTs has caused a fundamental change in power relations that is significant for social movements (Castells 2012). This new paradigm in social and political activism is based mainly on the benefits of the interaction between the internet and its users, which leads to the creation of new spaces for discourse, action, participation and mobilization. Regarding social movements, some scholars argue that the internet has complemented the repertoires of collective action and has become a decisive tool for movements' coordination and global diffusion (Garrett 2006). On the contrary, critics of digital action see the use of the internet as mainly negative, as social media are built around weak ties (Gladwell 2010, 45), and therefore are not sufficient to bring social and political change. Also, for authors such as Eugeny Morozov (2011), the internet offers a series of characteristics that can provoke political repression, and at the same time they do not allow social actors to mobilize themselves which means that more technology does not necessarily signify more democracy.

Whereas there is not much doubt that both citizenship and social movements are in flux as a result of the heavy use of digital media as both civic and political resources (among other factors), it is not always clear how these two fields are related to each other. Before getting into the description of a framework for studying citizenship in social movements, it is necessary to try to delineate their reciprocal relation, as well as to better understand their connections.

\section{Citizenship and Social Movements: How are they Linked and Why Does it Matter?}

Citizenship is often linked to notions of engagement, participation, membership and norms and values (Bellamy 2008) that are seen as necessary for practicing citizenship and, therefore, democracy. It simultaneously demarcates and describes a "set of institutions, practices and identities connected to people's aspirations for democracy" (Bosniac 2006, 11; cited in Svensson 2011a, 648). Citizenship is enacted, negotiated and practiced at a variety of sites, such as "the civil society landscape, the journalism domain, the advocacy domain and the 
alternative activist domain" (Dahlgren 2009, 168). Although all these loci are relevant to and important for the construction of citizenship, our focus here is on one of these sites, the locus of civil society and, more particularly, the contemporary social movements like 'Occupy' and the 'Indignados' movements, that have recently sprung up in many Western countries. The question that arises is how citizenship can be understood in late modern societies and, more particularly, within the contours of social movements. In attempting to delineate the relation between citizenship and social movements and the ways in which they are linked together, we come across four facts: (a) the alternative meanings of citizenship within social movements (b) citizenship as source for participation in social movements, (c) citizenship as a predominant frame of contemporary social movements and (d) social movements as a site for the construction and/or transformation of civic identities.

Firstly, by searching for the meaning of citizenship in social movements, we encounter alternative meanings of the civic, which point to current limits of the conception of traditional citizenship (Pell 2008; Cammaerts and van Audenhove 2005). Traditional conceptions of citizenship, based on membership and participation within a defined community (the nation state), make the notion inappropriate today. Today, membership does "not imply per se that the community can be bounded to a specific territory" (Svensson 2011a); rather, citizenship can be practiced and enacted outside territorial confines. Disentangling the notion of citizenship from the national state gives rise to post-national, transnational, global or cosmopolitan forms of citizenship (Isin 2009, 369). These developments have resulted in thinking the citizen less as a "legal subject", acting within "communities of birth" and more as a "normative subject" linked to several identities and actions within "communities of interest" (Giddens 1991; cited in Cammaerts and van Audenhove 2005, 182).

Another element of traditional readings of citizenship that is being challenged is its formal character, associated with sites and acts such as voting, social security and military obligation (Isin 2009, 371). Some scholars argue that values, rights and obligations are also undergoing a continual process of redefinition in late modern social landscapes (Svensson 2011a, 649) and that they acquire more informal than formal qualities. These informal qualities are considerably reshaping the way in which individuals see themselves as citizens and, therefore, their duties and responsibilities such as voting, paying taxes, helping in a community in a defined site. In the same vein, participation is no longer expressed only or primarily through a formal political process, but holds up within voluntary organizations, community associations and new social movements, which represent alternative forms of civic participation (Norris 2007, 638). The nation state seems inept to address this kind of specialized, identity or lifeand sub-politics (Beck 1994; Dahlgren 2009). Ulrich Beck called this development "the noninstitutional renaissance of the political": "Sub-politics means shaping society from below. In the wake of sub-politicization, there are growing opportunities to have a voice and a share in the arrangement of society for groups uninvolved in the substantive technification and industrialization process." (Beck 1994, 23).

Citizens can see their participation in social movements as "being much more gratifying and politically effective then being a member of an hierarchical (national) political party" (Cammaerts and van Audenhove 2005, p.182). This can be explained by the fact that in such spaces, citizens can identify with issue-related politics according to their personal interests (for example, ecology, immigration, financial crisis etc.) and less attached to ideology and representative political process. Anthony Giddens (1991) points out that these new processes 
within late modern societies are more some kind of lifestyle-based approach to participation, rather than a withdrawal from politics. Its significance is that this kind of political activity tends to be less dependent on traditional organizations, guided more by personal values than traditional ideologies, and focused more on single issues rather than across-the-board social change. Within such practices, citizenship is being rethought as a kind of unofficial, subjective, meso level activity, taking place in a variety of sites (bodies, courts, streets, media etc.) and performative actions (protesting, organizing, blogging, volunteering etc.); here, the emphasis is on the interaction between actors and the construction of common experiences, rather than a formal practice attached to a defined community.

Evidence of these practices comes in many forms. One indicator of the growth of such new civic practices that provides new meanings of the civic is the expansion of ICTs, marked, for example, by the growth of social networking, such as Twitter or Facebook, through which citizens gather signatures, organize common actions and protestation plans, and deliberate about issues. These practices make evident that civic engagement and participation shifts from a formal democratic level towards a more informal level of "unorganized citizens" and practices (Cammaerts and van Audenhove 2005, 182).

This approach allows us to conceptualize citizenship and, therefore, cultural and political participation as it unfolds, beyond the formal political terrain. In the face of new challenges experienced by democratic societies today, we need to consider not the "received dimension" of citizenship, based on a state-centred vision, but rather the "achieved dimension" of the civic, based on the achievement of agency through specific practices (Dahlgren 2009, 62). This kind of achieved citizenship that emphasizes active participation in society has its roots in theories of strong democracy (Barber 1984). Especially the republican perspective is based on an ethical dimension of citizenship, which in turn can provide an ideal for active participation of citizens in democratic self-governance (Dagger 2002, 150). This active participation can be achieved in civil society, where citizenship can be seen and studied "as agency, as achievement" (Dahlgren 2009, 63). In this terrain, citizens can pursue and share common political and social interests that in turn can prepare them for active civic participation and engagement. Citizenship outside of social movements (and, in general, outside civil society) risks to become reduced to weak and minimal forms of participation, in sites where citizens have little control and little ability to raise new issues or challenge dominant discourses.

All these characteristics can be summarized in Engin Isin's distinction between the "active citizen" and the "activist citizen" (2009). Isin argues that "how subjects act to become citizens and claim citizenship has [...] substantially changed" (ibid., 367). He describes the figure of active citizenship as the one that emerged during the French Revolution and persisted for two centuries (368), according to which the citizen is defined as a legal subject with singular loyalty, identity and belonging. His or her acts are "routinized social actions that are already instituted" (379). By contrast, activist citizenship refers to any act that produces subjects as citizens: subjects that "constitute themselves as those with "the right to claim rights" (371) in a variety of sites and scales. Here, "acts make a difference" as they "break routines, understandings and practices" (379); "they are not necessarily founded on law or on responsibility; rather, they call the law into question and may, sometimes, break it" (382). 
Secondly, citizenship can be seen as a starting point or a source for participation in social movements in at least two ways. At one level, civic values are a prerequisite for any kind of civic activity in voluntary associations or social movements, in the form of either substantive (for example, equality, liberty, justice, solidarity) or procedural values (for example, openness, responsibility, reciprocity and tolerance, willingness to follow democratic rules) (Dahlgren 2009, 110). Civic identity, then, serves as a prerequisite for citizens to become socially and politically active and engage as social members in the public life. At another, and perhaps more significant level, citizenship becomes a source for participation in social movements through its relative absence. As Isin explains, the historical transformations of citizenship, resulting in the recasting of established sites of citizenship (property, masculinity, warriorship) involved the "emergence of new actors that are constituted much less by what they possess than by what they ostensibly lack: strangers, outsiders and aliens had become claimants to citizenship" (2009, 376).

The history of citizenship is very much the history of those outsiders striving for redistribution and recognition on the basis of a new site of struggle (for example, gender, culture, sociopolitical attributes). In contemporary social movements, these new actors can be seen as not only individuals that lack formal citizenship (for instance, undocumented immigrants), but also as legal citizens who feel deprived of any real political power and efficacy. The notion of the national state as the primary site in which citizenship is realized is not convincing anymore for many citizens; rather, it seems feeble. In times of declining social services, growing class division and high rates of unemployment in many countries (in short, the disintegration of social rights), citizens' feelings of frustration, distrust and cynicism towards institutions of representations become the main drive towards participation in social movements, independent of traditional political organizations (Feixa et al. 2009). In other words, the deprivation of civic agency from contemporary citizens can be a trigger for social movement activity.

Thirdly, democratic citizenship emerges in new social movements as a predominant frame for participation, engagement and involvement, and civic identity serves as a predominant identity for movement actors. Contemporary social movements, such as the 'Indignados' or the 'Occupy' protesters, having distanced themselves decisively from traditional political actors and established groups or ideologies, use the notions of 'citizen', 'citizenship' and 'democracy' to build collective action frames for sharing common identifications or political claims (see Bennett and Segerberg 2012). A prime example is the Spanish movement 'Democracia real Ya!', which makes the demand for "real" democracy its main public slogan. Invoking the civic identity as a core identity for activists, allows these social movements not only to avoid identification with established political ideologies so distrusted by wide populations, but also to keep boundaries for participation fluid and open, accommodating a plurality of subjectivities that goes beyond any formal delineations of citizenship.

Fourth, the relation between citizenship and social movements is reciprocal, in the sense that civic identities not only serve as a precondition or a drive for participating in social movements, but are also constructed or transformed by this activity. Social movements are the sites where collective interests and identities are being discovered, forged and solidified, which is particularly evident in cases of subaltern or excluded subjectivities. Yet, besides the specific social, cultural and political demands each movement articulates, social movements help individuals develop into citizens, thereby evoking and constructing (some kind of) citizens. The concepts of liberal, republican and radical citizenship, among others (see Isin 
and Turner 2002), reveal that citizenship takes on quite different meanings in terms of values, practices and beliefs. The question that needs to be asked, then, is what kind of citizens contemporary social movements construct, or in other words, whether contemporary social movements give rise to civic identities significantly different from prior forms.

\section{Analysing Citizenship in Social Movements: A Preliminary Framework}

The review of the literature on citizenship does not offer explicit theoretical tools in order to make some clear assumptions regarding the configuration of contemporary citizenship, with all the new sites of struggle that challenge this notion today, including ICTs. In what follows, we attempt to outline a preliminary analytical framework, which could be used for uncovering the shape of citizenship within the activity of contemporary social movements, by addressing the following questions: What kind of citizenship figure is constructed within contemporary, ICT-mediated social movements? Are they "active citizens" or "activist citizens"? And what role do ICTs play in this process?

Isin underlines that "the challenge for theorists of citizenship is not to develop a theory of citizenship by fitting it into already existing 'political' theories [...]; rather it is to theorize citizenship in flux embedded in current social and political struggles that constitute it" (2009, 370). This calls for an approach open enough to identify the potential changes and shifts in the construction of civic identities. In this respect, Isin's typology of "active citizenship" and "activist citizenship" serves as a starting point for developing an approach that can capture the fluid and dynamic structure of citizenship. According to Isin "active citizenship has become a script for already existing citizens to follow already existing paths" (ibid., 383), whereas activist citizenship is understood as referring to "acts that transform forms (orientations, strategies, technologies) and modes (citizens, strangers, outsiders, aliens) of being political by bringing into being new actors as activist citizens (that is, claimants of rights) through creating or transforming sites and stretching scales" (ibid.).

That said, the proposed framework is developed along four axes, which correspond to the basic components of citizenship: membership, participation, engagement, and norms and values (Svensson 2011b). These components, or some combination of them, are usually present in the various classical definitions of citizenship and are mostly used in the field of citizenship studies. For instance, according to Jakob Svensson, "citizenship is often linked to privileges of membership of a political community (most often a nation state), privileges that consist of equal participation with fellow citizens on the making of the collective decisions that regulate social life of that political community" (2011a, 648). Furthermore, we adopt the distinction between tangible resources and ideational resources, which is used for the analysis of social movements (van Stekelenburg and Klandermans, 2009). The former is used to signify (mobilization) practices, while the latter refers to the (subjective) meaning of actions for engaged actors.

This framework is inspired by the classical components of citizenship as represented in the field of citizenship studies and, therefore, does not consist of a reconceptualization of Dahlgren's civic cultures framework. Although that framework appears ideal, it seems more appropriate empirically when investigating citizenship, in a variety of sites or spheres (from the political sphere to the sphere of entertainment), it would prove inadequate for addressing 
the particularities of experiences within social movements. Having said that, and considering the generic nature of this framework, we believe that it cannot be applied to and elucidate the different and particular processes of the context of social movements. For these reasons, we attempted to develop a framework which pays more attention to the context of the study (social movements), using concepts that draw mainly on social movements' and citizenship studies, which Dahlgren does not use so much in his framework. These come under four headings that represent the four axes of the theorization of citizenship: membership, engagement, participation, and norms and value.

\section{Membership}

If we examine the broad issue of citizenship, we observe that membership constitutes its core, and, since the Greek polis, the two concepts are closely linked. The tangible aspects of membership refer to the concrete rights and obligations of individuals, tied to a political community with some kind of authority (Svensson 2011b). In this sense, citizenship is understood primarily as status and is defined as membership of individuals in a nation state or a group with rights and obligations at a specified level of action. "Citizenship begins with determining membership in a nation-state which means establishing 'personhood' or who out of the totality of denizens, natives and subjects of a territory as being citizens with specific rights" (Janoski and Gran 2002, 13). Membership as a "bounded" notion refers to the act of a person "who by living in the city, participated in a process of civilization" (Isin and Turner $2002,5)$. At the same time, it is also worth considering the ideational aspects of membership, which refer to the meaning actors ascribe to the status of citizenship (or the lack of this status). This approach allows us to distance ourselves from the modern figure of the citizen "with singular loyalty, identity and belonging" (Isin 2009, 368) and question the levels of commitment, identification and belonging with the political community in question, for example the nation state, or explore the possibly multiple and complex layers of such feelings. For instance, there can be 'legal citizens' who resist identification with the nationstate for ideological reasons (for example, anarchists) and 'non-legal citizens' (for example, "undocumented" immigrants) who, despite the lack of formal citizenship, develop a feeling of civic commitment to the state of residence.

The notion of bounded membership entails rights and obligations, which derive from individuals' status as legal actors. These legal actors can accomplish social or political acts within the borders of the nation-state, due to the fact that they hold the legal status of citizenship. These are Isin's “active citizens". To give a timely example, at the time of writing quite large protests taking place in France against the legislation allowing the same-sex marriage in France; these protesters are active citizens, since holding the legal status of citizenship (being French citizens) allows them to protest against the legislation that rules their lives. However, their actions and their demands do not exceed or challenge the established boundaries of citizenship, neither in terms of actors, nor in terms of scale or sites, as they evolve within the "fixed and given boundaries" of the nation state (Isin 2009, 370).

Nevertheless, today it is no longer adequate to think of states as the unique entity of membership or scale of citizenship. Isin (2009) puts forth citizenship as process or "an instituted subject position"; in this understanding actors of citizenship are not necessarily those who hold the status of citizenship; rather, it can be performed by various categories of subjects, such as aliens, migrants, refugees, states, courts etc." (ibid., 370). This unbounded 
notion of membership resembles a "form of identification, a type of political identity; something to be constructed, not empirically given" (Mouffe 1992, 231). It is also inevitably related to the emergence of "transnational communities of discourse developed by a plurality of (transnational) social movement organizations (e.g. being a member of an online community)" (Mouffe 1992; cited in Cammaerts and van Audenhove 2005, 157). Thus, active citizenship can entail those acts that, in terms of either actors or scales, challenge the established boundaries of citizenship for example, when actors constitute themselves (and others) as subjects of rights (Isin 2009). One such example could be the French movement "Ni putes ni soumises", which protests the living conditions of Arab women in France and in the world. This type of action is more likely to create 'rupture' due to the actors involved as claimants of rights and the scale that exceeds the boundaries of the nation state. In contrast to the previous categorization, these actions are "fluid and dynamic", and "are formed through contests and struggles, and their boundaries become a question of empirical determination" (Isin 2009, 370).

\section{Participation}

Another decisive aspect of citizenship has to do with the participation of the citizens in the social and political life of a community (Dahlgren 2009). Participation is so important for citizenship that it is claimed that it can even be equated with citizenship (Svensson 2011a, 650). Isin considers "the theorization of acts, and therefore the shift from what people say to what people do, an important supplement of existing studies about citizenship" $(2009,371)$. Identifying participation as tangible and ideational resources allows us to focus not only on the acts themselves, namely the various repertoires of collective action within social movements, but also on how involved actors interpret and make sense of these acts, particularly in terms of what it means to be a citizen.

Going back to Isin's typology of the "active" and "activist" citizenship, we can distinguish a formalistic view of participation, which in representative democracies goes to a large extent through ancient institutional channels, and conventional routinized procedures such as elections and voting, opinion polls and referenda, taxpaying, social security, military service etc. This perspective mainly refers to the "active citizen", who acts within the given script of representative democracy. Yet, as Isin notes, "whereas these acts can make a difference under certain conditions, they cannot create a rupture" - as, for example, the movement of sanspapiers did by creating a series of acts of citizenship that brought some fundamental injustices of republican citizenship to the fore (McNevin 2006, 135; cited in Isin 2009, 381).

Consequently, it is important to also explore the informal dimension of participation, which has become a widely discussed phenomenon of late modern societies. Issue campaigns, social and political activism, public assemblies, as well as acts of civic disobedience such as the long-term occupation of public spaces, stand out as prominent repertoires of action within contemporary social movements (Norris 2007). In fact, the latter constitute the space par excellence where rupture can be created: "social movements are defined in part by their use of non-institutionalized means of action, such as appropriating and using public and quasi public places for purposes other than those for which they were designed or intended" (Saule and Kriesi 2004, 6). An example that clearly demonstrates how bodies can become new sites of 
contestation, not unlike the situationist notion of "détournement", is the activity of FEMEN, the organization of women activists who engage in topless protest in public places and in various countries of the world against gender and social oppression and inequalities, giving rise to a new conception of citizenship, namely sexual or gendered citizenship (Lister 2002), which contests the established boundaries of citizenship as far as gender is concerned. Other informal activities entail the use of new media and particularly social networking sites, that have emerged as civic resources, important informal modes of participation and, at times, significant sites of struggle. Activists engage routinely in debating issues on Facebook and Twitter, creating online protest groups, blogging, organizing events online and offline, creating and signing petitions etc.

The question that needs to be further explored is whether, and in which ways, online spaces and tools serve as a terrain for acts of activist citizenship instead of active citizenship and move beyond simply sustaining organized protest activities or complementing already existing institutionalized channels for participation. At the same time, interrogating the subjective side of practices (how acts are interpreted by actors) can help us understand the extent to which citizens are enacted and empowered through such activity.

\section{Engagement}

The third axis of citizenship is engagement. Engagement differs from participation since the latter is seen as practices, while the former is seen as a will that urges citizens to participate. Engagement refers to "subjective states, that is, a mobilized focused attention on some object. It is in a sense a prerequisite for participation" (Dahlgren 2009, 80). In the civic domain, disengagement may be interpreted as a negative evaluation of the political system, translated into indifference and distrust, which signals a critical distancing of citizens from formal participation and therefore the state of "received citizenship". The essence of received citizenship is based on a more state-centred and passive form of citizenship in which "citizens are making strategic use of their formal rights and guarantees to further expand the democratic character of society (Dahlgren 2009, 62). The meaning of engagement can be defined as "achieved citizenship", which refers to a form of citizenship that is constructive and acquired by being engaged in political actions, associated more with a sense of political efficacy rather than with a formal duty. This "achieved" dimension of citizenship is taking place through the extent (rules and norms pertaining to inclusion and exclusion), content (addressing rights and responsibilities) and depth of citizenship (what Dahlgren refers to as "thickness" and "thinness"), and is associated with the meaning of civic identities in a given society (Dahlgren 2009).

\footnotetext{
2 The French term "détournement" was introduced by Guy Debord and the Situationist Internationalist movement of the 1960s. It can be described as lifting an image or a symbolic text from its original context and setting it in a new one (Coyer et al. 2007, 168), so that it carries unintended radical messages (Waltz 2005, 111). In the hands of media activists or culture jammers, this technique is used to subvert meanings embedded in the commercial use of images, fighting advertising with its own weapons. We can identify the practice of détournement in FEMEN's particular appropriation of the female naked body, as they tend to transform it from a vehicle for selling products in commercial advertising to a powerful means of fierce political expression.
} 
As engagement is taken to refer to a will or a feeling, it is mainly of ideational nature. Yet, conceptually, it may also be examined in tangible terms through the study of specific practices in which it is translated. Again, to study civic engagement in social movements we can distinguish between an "active" and "passive" dimension in (Cammaerts and van Audenhove, 193) typology. The active engagement "can be translated into attending protests, other forms of direct actions, doing voluntary work, participating in meetings or being actively involved in an organization" (ibid., 184). The passive engagement relates to the formal type of membership without strong identification or actual participation, for example, being present in a meeting without really participating (ibid.). This distinction can be particularly useful in studying online activities, which generally tend to be considered a priori signs of active engagement. To give an example, posting messages or participating in an online forum or other direct actions can be seen as active engagement, in contrast to being an inactive member of a Facebook page or following Twitter users without posting anything, which can be seen as rather passive.

\section{Norms and Values}

Norms and values constitute the backbone of citizenship, and therefore cannot be left out of the analysis. As previously stated, substantive or procedural values are democratic ideals that help maintain the democratic character of society (Dahlgren 2009). As Dahlgren points out, "democracy requires civic cultures that underscore the commitment to both the rules of the game and to larger visions of a democratic society" (ibid., 5). Citizens need to agree on some basic conceptions and values, in order to be able to pursue their own individual interests and desires within a democratic society. Values articulate the identity of the citizen and are mostly used to define politics (and the limits of the legal system) and how it ought to be practiced. What binds "citizens together is a common recognition of a set of ethico-political values" (Mouffe 1992, 235).

Different values point to different models of citizenship and, therefore, of democracy, such as liberal, republican, communitarian or radical conceptions (see Isin and Turner, 2002). For instance, in liberal democratic polities, primary political values are individual liberty, autonomy, consent and limited state power (Schuck 2002). To study the civic identities that are being constructed and reconstructed within social movements, we need to focus on the sets of norms and values that are adopted by involved actors. In this context, an "activist citizenship" would consist of those values that identify and expose the exclusions and inequalities inherent in any given established order and institutional arrangement, and seek to "introduce a break" (Isin 2009). To this end, we need to study the civic discourses that are articulated within collective action in social movements, apart from their explicitly political ideologies and demands. An example is the movement of 'Democracia real Ya!, which in its manifesto makes claims for direct democracy through advocating the change of the constitution in its communiqués, public interviews or social media. These kinds of claims and discourses could lead to a radical democratic citizenship (Brown and Rasmussen 2002).

Although it is evident that values are understood more as an ideational aspect than a tangible component of citizenship, ideological values are also embedded in technological structures and artefacts. Besides the general underlying structure of popular online platforms (for example, Facebook), the analysis of which is beyond the scope of the current article, it is important to analyse the ideological dimensions of online tools and spaces and of the ways in 
which they are put to use by involved actors. For instance, it is important to study the extent to which online spaces and tools, used by social movements, enable or disable representative forms of participation based on hierarchical structures of organization within the movement or, instead, more direct forms of participation based on openness and horizontal organization (see Kavada 2013).

\section{Conclusion}

The recent protest movements that have sprung up in many countries, constitute a new phenomenon that deserves to be studied on its own right, not only as a form of social movements per se, but also with regard to the role of digital technologies in collective action. Nonetheless, in this paper we have argued for an approach that goes beyond the movements' direct demands aiming to examine how citizenship is constructed within such movements. Citizenship seems to function as a significant point of departure, but also as an overarching frame for contemporary movement activity. At the same time, movements are the prime site where citizenship can be enacted and citizens be born (and reborn).

Although this question can only be answered by the empirical study of social movements that have integrated online resources well into their routine action repertoires, we have suggested four ways in which citizenship and social movements are interrelated. Firstly, citizenship seems to function as a significant point of departure for political mobilization within social movements, not only in the form of a set of dispositions and values necessary for the construction of active political subjects, but more importantly through the deprivation of real civic agency and efficacy experienced today by citizens and non-citizens in several parts of the world. Secondly, citizenship seems to function as an overarching frame for contemporary movement activity, as social movements invoke the civic identity as their core identity, distancing themselves from established political ideologies and at the same time accommodating a plurality of subjectivities. Thirdly, contemporary social movements appear to constitute a site where citizenship acquires alternative meanings and translates to alternative practices, such as civic identities 'unbounded' from the nation-state and its official political agents, and activities taking place in a variety of sites and performative actions. Last but not least, civic identity within social movements becomes a dynamic process, subject to reconstruction or transformation according to the lived experiences of movement activists. In other words, movements are the prime site where citizenship can be produced and enacted.

A question that bears empirical study is what kinds of citizens are produced within current constellations of social movements. Are they simply active citizens or can we speak of activist citizens? To begin addressing this question, we have outlined a preliminary framework for analysing citizenship along the four axes of membership, participation, engagement and norms/values, in both tangible and ideational terms, that could be applied for understanding "what makes the citizen", as Isin (2009) proposes, and how ICTs contribute to this making. 


\section{References}

Anduiza, E., Cristancho, C. \& Sabucedo, J. M. (2012) 'Mobilization Through Online Social Networks: The Political Protest of the Indignados in Spain', ICTlogy.net, [online]. Accessilbe at http://ictlogy.net/bibliography/reports/projects. php?idp=2400. Accessed 10 March 2013

Barber, B. (1984) Strong Democracy: Participatory Politics for a New Age, Berkeley: University of California Press

Beck, U. (1994) 'The Reinvention of Politics: Towards a Theory of Reflexive Modernization', in U. Beck, A. Giddens and S. Lash, Reflexive Modernization" Politics, Tradition and Aesthetics in the Modern Social Order, Cambridge: Polity Press, pp. 1-55

Bellamy, R. (2008) Citizenship: A Very Short Introduction, New York: Oxford University Press

Bennett, L. (2003). 'New Media Power: The Internet and Global Activism', in N. Couldry and J. Curran (eds), Contesting Media Power: Alternative Media in a Networked World, Lanham: Rowman and Littlefield, pp. 17-37

Bennett, L. and Segerberg, A. (2012) 'The Logic of Connective Action', Information, Communication \& Society, 15(5), 739-68

Bosniak L. (2006) The Citizen and the Alien: Dilemmas of Contemporary Membership, New Jersey: Princeton University Press

Brown, M., and Rasmussen, C. (2002) 'Radical Democratic Citizenship: Amidst Political Theory and Geography', in E. Isin and B. Turner (eds), Handbook of Citizenship Studies, London: Sage, pp. 175-89

Cammaerts, B. and van Audenhove, L. (2005) 'Online Political Debate, Unbounded Citizenship, and the Problematic Nature of a Transnational Public Sphere', Political communication, 22(2), 179-96

Castells, M. (2012) Networks of Outrage and Hope: Social Movements in the Internet age, Cambridge: Polity Press

Coyer, K., Dowmunt, T. and Fountain, A. (2007) The Alternative Media Handbook. London: Routledge

Dagger, R. (2002) 'Republican Citizenship' in E. Isin and B. Turner (eds), Handbook of Citizenship Studies, London: Sage, pp. 145-58

Dahlgren, P. (2002) 'Doing Citizenship, the Cultural Origins of Civic Agency in the Public Sphere', Cultural Studies, 9(3), 267-86

Dahlgren, P. (2009) Media and Political Engagement: Citizens, Communication and Democracy, Cambridge: University Press 
Feixa, C., Pereira, I., and Juris, J. (2009) 'Global Citizenship and the "New, New" Social Movements: Iberian Connections', Young, Nordic Journal of Youth Research, 17(4), 421-42

Garrett, K. (2006) 'Protest in an Information Society: A Review of Literature on Social Movements and New ICTs', Information, Communication and Society, 9(2), 202-24

Gerbaudo, P. (2012) Tweets and the Streets: Social Media and Contemporary Activism, London: Pluto Press

Gladwell, M. (2010) 'Small Change: Why the Revolution will not be Tweeted', The New Yorker, 4 October,42-49

Giddens, A. (1991) Modernity and Self-identity: Self and Society in the Late Modern Age, Cambridge: Polity

Hermes, J. (2006) 'Citizenship in the Age of the Internet', European Journal of Communication, 21(3), 295-309

Isin, E. (2009) 'Citizenship in Flux: The Figure of the Activist Citizen', Subjectivity, 29, $367-88$

Isin, E., and Turner B. (2002) 'Citizenship Studies: An Introduction', in E. Isin and B Turner (eds), Handbook of Citizenship Studies, London: Sage, pp. 1-10

Janoski, T. and Gran, B. (2002) 'Political Citizenship: Foundations of Rights', in E. Isin E. and B. Turner (eds), Handbook of Citizenship Studies, London: Sage, pp. 14558

Kavada, A. (2013) 'Internet Cultures and Protest Movements: The Cultural Links Between Strategy, Organizing and Online Communication', in B. Cammaerts, A. Mattoni and P. McCurdy (eds), Mediation and Protest Movements, Bristol: Intellect, pp. 75-94

Kriesi, H., Koopmans, R., Duyvendak, J. W., \& Giugni, M. (1995) New Social Movements in Western Europe: A Comparative Analysis, Minneapolis: University of Minnesota Press

Lister, R. (2002) 'Sexual Citizenship', in E. Isin and B. Turner (eds), Handbook of Citizenship Studies, London: Sage, pp. 191-207

Morozov, E. (2011) The Net Delusion: The Dark Side of Internet Freedom, New York: Public

Mouffe, C. (1992) Radical Democracy, London: Verso

Norris, P. (2007) 'Political Activism: New Challenges' in E. Boix and T. Stokes (eds), The Oxford Handbook of Comparative Politics, New York: Oxford University Press, pp. $628-49$

Olsson, T. (2008) 'For Activists, for Potential Voters, for Consumers: Three Modes of Producing the Civic Web', Journal of Youth Studies, 11(5), 497-512 
Pell, S. (2008) 'Making Citizenship Public: Identities, Practices and Rights at Woodsquat', Citizenship Studies, 12(2), 143-56

Putnam, R. (2000) Bowling Alone: The Collapse and Revival of American Community, New York: Simon \& Schuster

Schuck, P. (2002) 'Liberal Citizenship' in E. Isin and B. Turner (eds), Handbook of Citizenship Studies, London: Sage, pp. 131-44

Saule, H and Kriesi, H. (2004) The Blackwell Companion to Social Movements, Oxford: Blackwell

Svensson, J. (2011a) 'Theorizing Citizenships in Late Modern ICT Societies', tripleC, 9(2), 644-56

Svensson, J. (2011b) 'The Expressive Turn of Citizenship in Digital Late Modernity', Journal of Democracy, 3(1), 42-56

Touraine, A. (1978) La voix et le regard. Sociologie des mouvements sociaux [The Voice and the Sigh: Sociology of Social Movements], Paris: Seuil

van Stekelenburg, J., and Klandermans, B. (2009) 'Social Movement Theory: Past, Present, and Prospects', in S. Ellis and I. van Kessel (eds), Movers and Shakers: Social Movements in Africa, Boston: Brill, pp. 17-43

Waltz, M. (2005) Alternative and Activist Media, Edinburgh: Edinburgh University Press 